\title{
Entre tradición y renovación: manifestaciones del horror ficcional en la narrativa breve de Emilio Carrere
}

\section{Between Tradition and Renovation: Shapes of Fictional Horror in Emilio Carrere's Short Narrative}

\author{
Andrés Sánchez Martínez \\ Universidad de Granada \\ andressanchez605@gmail.com \\ ORCID iD: https://orcid.org/0000-0002-9602-0879
}

\section{RESUMEN}

Este artículo se centrará en las diferentes formas que adquiere el horror en algunos relatos cortos de Emilio Carrere. Para ello, se partirá de una concepción teórica del horror como una de las consecuencias del efecto fantástico en las obras estudiadas. En estos casos, Carrere construye una atmósfera sobrenatural sirviéndose de procedimientos como la recurrencia a motivos de la tradición gótica, al ocultismo tan popularizado en el ambiente modernista o a la introducción de lo insólito por medio de técnicas metaficcionales. Todos estos discursos entrarán además en contacto con el habitual elemento humorístico de la narrativa del autor madrileño, que servirá tanto para desarticular como para acentuar lo fantástico. En última instancia, los elementos fantásticos en la obra de Carrere se revelan como muestras indispensables de otra de las múltiples caras ocultas del modernismo, para cuestionar en esta ocasión las certezas de lo real.

Palabras Clave: literatura fantástica; horror; ocultismo; modernismo.

\section{ABSTRACT}

This article will focus on the analysis of the different ways of horror in some short stories by Emilio Carrere. For this reason, we will start from a theoretical conception of horror which considers it as a consequence of the fantastic effect in the works under study. In these cases, Carrere constructs a supernatural atmosphere thanks to several procedures like the use of gothic motifs, the occultism trends (very popular in Spanish Modernism) and the introduction to uncanny situations through metafictional methods. All these discourses contact with the usual humorous elements of the Madrilenian author's narrative, which will serve not only to break down the fantastic elements but also to emphasise them. Ultimately, these fantastic elements in Carrere's work reveal themselves as essential evidence for another of the numerous faces of Spanish Modernism, in order to question the presumed certainty of reality.

Key words: Fantastic literature; Horror; Occultism; Spanish Modernism. 
Algunos períodos como el modernismo y las primeras décadas del siglo $\mathrm{XX}$ son conocidos en literatura sobre todo por sus grandes figuras consagradas por el canon. Sin embargo, todavía actualmente parte de la obra de escritores canónicos es condenada al olvido o al desprecio en su clasificación como «obra menor». Esto suele ocurrir con aquella parte de su producción dedicada al género del cuento fantástico, configurando así una etapa más de lo que David Roas y Ana Casas llaman «una tradición fantástica española» ${ }^{1}(2008,9)$. A pesar de ello, el canon usualmente ha prestigiado el «realismo» como característica definitoria de la narrativa española, «condenando a la marginación a toda manifestación literaria no realista» $(2008,10)$. Quizás se encuentre en este hecho una de las causas del menosprecio de autores como Emilio Carrere (1881-1947), que no dudó en incluir un sesgo marcadamente sobrenatural a muchos de sus textos, tanto poéticos como narrativos. A través de una breve selección de algunos relatos $\operatorname{cortos}^{2}$ del autor madrileño nos centraremos aquí precisamente en esta vertiente de su obra, que buscó trazar una compleja línea entre tradición y renovación en el horizonte literario de principios del novecientos.

\section{IMPLiCACIONES DE LO FANTÁSTICO}

Antes de adentrarnos en la obra de este escritor y analizar la presencia de los elementos fantásticos en su narrativa, conviene primero tomar conciencia de la naturaleza de los mismos. En este caso, se entiende lo fantástico como «categoría estética»; lo que implica, más allá de interpretaciones puramente estructuralistas, que «lo fantástico va a depender siempre [...] de lo que con-

${ }^{1}$ David Roas recogió en 2003 buena muestra de esta tradición cuentística hispánica a través de su antología Cuentos fantásticos del siglo XIX (Mare Nostrum, Madrid). En esta recopilación se sitúa el inicio de lo fantástico moderno en «Luisa» (1835) de Eugenio de Ochoa, para pasar después a relatos indispensables como «La madona de Pablo Rubens» (1837) de Zorrilla o «El monte de las ánimas» (1861) de Bécquer. Es seguro que Carrere tuvo que conocer estos textos, así como los de sus contemporáneos Emilia Pardo Bazán, Rubén Darío, Ramón del Valle-Inclán, Eduardo Zamacois, Antonio de Hoyos y Vinent o Mario Roso de Luna, al que le unía una gran amistad (Cruz Casado 1994, 24-31).

2 Este trabajo deja a un lado el análisis de los elementos de horror en la novela extensa de Carrere (La torre de los siete jorobados, 1924), limitándonos en esta ocasión a analizar algunas formas del horror ficcional en una selección de textos pertenecientes a su narrativa corta. Un análisis más completo del tema debe extenderse a futuros trabajos, habida cuenta de la complejidad genérica de su novela larga (entre otras formas de hibridismo, puede destacarse la unión que presenta entre lo fantástico y lo policiaco), así como al ingente volumen de relatos y novelas breves del autor madrileño, sobre el que todavía no se ha realizado una catalogación completa. Junto a los relatos que se analizarán aquí, Cruz Casado destaca la filiación fantástica de otros textos, como la novela corta Las inquietudes de Blanca María (1922) (1994, 29). 
sideremos como real» (Roas 2011, 11 y 15). Las diversas poéticas de lo fantástico comparten siempre una base, un modo de representación no mimético, en tanto que la literatura plantea un choque con el entorno del lector y un extrañamiento, de forma que los fenómenos presentados no sean susceptibles de una explicación racional. «El relato fantástico presenta, pues, lo inexplicable y contradictorio de la realidad, hace intervenir lo inverosímil, de modo que el orden establecido queda en entredicho gracias a un fenómeno que se sale de sus reglas de juego, enfrentando, además, evidencia y verosimilitud» (Pérez 1994, 21). Por tanto, el profundo carácter subversivo de lo fantástico no implica una completa abstracción de lo real, sino que lo inexplicable emana de un entorno concreto (el del sujeto productor del texto). Así, puesto que el elemento sobrenatural supone un diálogo con la realidad, es preciso observar cómo lo fantástico se muestra plenamente «historizable». Por ello, resulta evidente que este tipo de discursos no adoptarán las mismas formas antes del siglo XVIII y los textos que Tzvetan Todorov llamaba «maravillosos» (1999, 46-49) que a partir de la Ilustración y el racionalismo, o conviviendo con el sentimiento de lo «sublime» dieciochesco ${ }^{3}$.

Un breve recorrido por la historia de la literatura fantástica puede arrojar valiosos elementos de reflexión sobre su naturaleza cambiante, que no obedece únicamente a condicionantes retóricos, sino también sociales. Así, algunos teóricos han defendido ya la dependencia del discurso fantástico de su contexto sociocultural (Roas 2001, 20), al que sería útil añadir el concepto clave de «ideología» (Eagleton 2005, 52-55) o «inconsciente ideológico» ${ }^{4}$ (Rodríguez 1990, 15 y 25), la estructura más profunda desde la que emerge el texto. Las

3 Se suele coincidir en determinar el comienzo de la literatura fantástica hacia mediados del siglo XVIII, sobre todo como consecuencia de la novela gótica inglesa y del Schauerroman alemán (Carroll 2005, 129). Estas formas narrativas ofrecían, a través de la recurrencia a lo sobrenatural, una visión de ese «lado oscuro de la realidad y del yo que la razón no podía explicar» (Roas 2011, 19), cuya «extrañeza» ya se teorizaba en los múltiples ensayos sobre lo «sublime» desde Addison, Burke o Kant, para pasar a la exaltación por el romanticismo y su principal potencia creadora, la imaginación (2011, 18-19). De esta forma, no cabe hablar de literatura fantástica con anterioridad al siglo XVIII, sino de discursos «maravillosos» (Todorov 1999, 37 y 46-49; Roas 2001, 10), en donde lo sobrenatural no pone en duda lo real, sino que forma parte de sus reglas de funcionamiento. Así, la existencia de los dragones en la épica germánica o de la magia del Grial en los ciclos artúricos son perfectamente naturales si se analizan desde el punto de vista de la lógica medieval, articulada en torno a una concepción religiosa-maravillosa del mundo.

${ }^{4}$ Las teorías formuladas por el profesor Juan Carlos Rodríguez acerca de la «radical historicidad de la literatura» han permitido penetrar no solo en aquello que origina los textos, sino en la misma causa de los mismos y de su construcción: «la lógica del sujeto no es otra cosa que una derivación -una invención de una matriz ideológica determinada-. [...] Los discursos literarios (o cualesquiera otros de cualquier formación social, anterior o posterior) están siempre -y únicamente- segregados desde (y determinados por) las necesidades específicas de una matriz ideológica históricamente dada. [...] La literatura $[\ldots]$ es el producto 
obras que analizaremos mostrarán de forma más o menos directa ese espacio de radical trascendencia, aunque de escurridizas formas. Lo que sí se encuentra en la superficie de los textos es la variada filiación estética de Carerre con la multitud de «direcciones renovadoras» (Gullón 1990, 20) planteadas por el modernismo, entre las que lo fantástico adquiere un peso de suma importancia. Ahora bien, para delimitar este espacio estético e ideológico resulta imprescindible refutar el juicio tan manido acerca de lo fantástico como vehículo de escape de la realidad (Roas 2001, 15) o de la existencia de un «modernismo preciosista» de evasión (Gullón 1990, 77-78 y 82). Como demuestra el análisis profundo de los textos, ambos sistemas unidos elaboran una propuesta a una realidad utilitarista con la que el escritor no está de acuerdo ${ }^{5}$.

\section{Peculiaridades de lo fantástico en la obra de Emilio Carrere}

\subsection{Hacia el efecto de horror: antecedentes}

Junto a la naturaleza mutable de lo fantástico destaca su doble motivación. En primer lugar, al igual que todos los mitos y motivos tradicionales que puede albergar, esta literatura necesita evolucionar para seguir sorprendiendo al lector (Borges 1979, 191). En segundo lugar, el diálogo ya presentado entre lo fantástico y la realidad sociocultural de la que surge también propicia una evolución. Ahora bien, ¿qué dimensiones adquiere lo fantástico en Carrere? En general, como vehículo predilecto de entrada a lo imposible, el autor madrileño se sirve de las leyendas ${ }^{6}$ y el ocultismo. Solo con esto puede sospecharse ya el matiz tenebroso que prolifera en sus textos, que buscan

peculiar de un inconsciente ideológico segregado desde una matriz histórica, propia de unas relaciones dadas» (Rodríguez 1990, 8, 15 y 25).

${ }^{5}$ En este sentido, Ricardo Gullón afirma que «el poeta vive en la realidad [social] y se nutre de cuanto en ella crece; si la niega es por no encontrarla según la desea, por hallarla desustanciada, exhausta, sin vitalidad [...] completando la creación en su obra personal, a la que incorporará lo que su medio no puede proporcionarle [...]. El exotismo modernista [y lo fantástico] no es pretexto para negarse a la realidad, sino medio para rectificarla» (1990, 77-78 y 82 ).

${ }^{6}$ El sustraro legendario y la nota fantástica de la narrativa carreriana han sido repetidamente señalados. No obstante, ello solía concluir en el desprecio de su obra, tachada de poco original, lo que ha impedido un acercamiento a sus textos libre de prejuicios: «Es Carrere, como novelista, un escritor desdibujado e intercambiable, a pesar de su fecundidad y de la relativa inquietud que le hace abordar tipos y temas diversos. [...] Vacilando y recogiendo, según oportunidad [...] que le brindan los asuntos y el momento literario, elementos casi siempre envejecidos ya, del folletín, de la novela erótica, del costumbrismo neorromántico, o de la prosa y el espíritu arcaizantes y formalistas del modernismo en decadencia, pocas páginas novelescas suyas pueden leerse hoy con admiración o interés» (Nora 1973, 353). 
continuamente alcanzar el efecto de horror en el lector, aspecto ya debatido desde la literatura gótica:

The recollection of a star, an unknown world, are all circumstances which excite forlorn, melancholy, and solemn feelings, and dispose us to welcome, with trembling curiosity, the awful being that draws near; and to indulge in that strange mixture of horror, pity, and indignation, produced by the tale it reveals (Radcliffe $1826,147-148)$.

Así delimitaba Ann Radcliffe en su artículo «On The Supernatural in Poetry» (1826) su concepción de horror, como parte de un conjunto de «solemnes sentimientos» que los grandes poetas debían suscitar al lector, que con «temblorosa curiosidad», se vería embargado simultáneamente por emociones como piedad, horror e indignación. Como se puede deducir de estas nociones, la autora seguía de cerca la dilatada tradición filosófica que desde Longino se fijaba en el concepto de «lo sublime», una de las más trascendentales categorías estéticas de la historia del arte occidental.

En torno a lo sublime se polarizaron gran parte de los estudios de estética del siglo XVIII, entre ellos la obra de Edmund Burke (Indagación Filosófica sobre el origen de las ideas acerca de lo sublime y lo bello, 1759) e Inmanuel Kant (Observaciones sobre el sentimiento de lo bello y lo sublime, 1764). Interesa retrotraerse hasta este punto porque Burke (a quien Radcliffe cita reiteradamente en su artículo) definía lo sublime en contacto estrecho con su concepto de terror (cercano, de alguna manera, a su concepción de horror): «Todo lo que resulta adecuado para excitar las ideas de dolor y peligro, es decir, todo lo que es de algún modo terrible, o se relaciona con objetos terribles, o actúa de manera análoga al terror, es una fuente de lo sublime; esto es, produce la emoción más fuerte que la mente es capaz de sentir» (Burke 2014, 79). De forma análoga ya se había pronunciado Joseph Addison en Los placeres de la imaginación (1712):

Consideraré primero aquellos placeres de la imaginación que nos da la vista presencial y el examen de los objetos exteriores. Yo juzgo que todos ellos dimanan de la vista de alguna cosa grande, singular, o bella. A la verdad en un objeto puede encontrarse alguna cosa tan terrible y ofensiva, que el horror y disgusto que excita supere al placer que resulta de su grandeza, novedad o belleza. Pero aún entonces acompañará a este horror y disgusto una mezcla de placer proporcionada al grado en que sobresalga y predomine alguna de estas tres calidades (Addison 1991, 137-138).

De esta forma, el XVIII sentaría las bases teóricas de la estética del horror. La consecuencia última de ello será la consideración de lo horrible como elemento crucial para alcanzar placer estético en la obra de arte, persiguiéndose así la armonía ideal entre la belleza y el horror. Evidentemente, a partir de la novela gótica, la balanza se inclinará preferentemente por uno de los dos extremos. 
La novela gótica, con Ann Radcliffe a la cabeza, al tiempo que practicaba las enseñanzas estéticas sobre lo sublime y el horror, concretaba la naturaleza del objeto que suscitaría emociones de tal violencia. No servía cualquier realidad, sino que se prefería lo turbulento, aquello que rompiera con las leyes establecidas, lo sobrenatural:

I do not absolutely know that spirits are permitted to become visible to us on earth; yet that they may be permitted to appear for very rare and important purposes, such as could scarcely have been accomplished without an equal suspension, or a momentary change, of the laws prescribed to what we call Nature -that is, without one more exercise of the same Creative Power of which we must acknowledge so many millions of existing instances, and by which alone we ourselves at this moment breathe, think, or disquisite at all, cannot be impossible and, I think, is probable (1826, 148-149).

De esta forma, Radcliffe especifica cómo el poder creador del poeta debía oponerse a las leyes naturales, o como añadiría David Punter, sobrepasarlas $(1980,407)$. No importaba ya la racionalización externa de los seres sobrenaturales poetizados, sino que el creador debía hacerlos posibles en el arte. Sobre esta suspensión del orden natural teorizaría un siglo después H. P. Lovecraft en su ensayo El horror sobrenatural en la literatura (1927):

Debe haber cierta atmósfera de intenso e inexplicable pavor a fuerzas exteriores y desconocidas; y una alusión, expresada con una gravedad y una execración que se convierten en el tema principal, a esa idea sumamente terrible para el cerebro humano: la maligna y concreta suspensión o rechazo de las leyes fijas de la Naturaleza que son nuestra única salvaguardia frente a los ataques del caos y de los demonios del espacio insondable (Lovecraft 2010, 31).

Así, el autor estadounidense concretaba todavía más el efecto de horror. Sin pensar tanto en los grandes poetas ingleses que se habían servido de situaciones violentas para suscitar esta emoción (para Radcliffe, Shakespeare y Milton sobre todo), Lovecraft consideraba lo horrible como consecuencia indispensable de todo relato fantástico. De esta forma, se marcan diferencias notables con posteriores concepciones del horror en tanto que subgénero del «cuento de miedo» (Bravo Rozas 2013, 58-61). Para Lovecraft, el horror representa una consecuencia necesaria del discurso fantástico y de su efecto de desconfianza en el lector que se enfrenta a una realidad inexplicable.

\subsection{Hacia el efecto de horror: mecanismos constructivos}

Antes de la primera publicación del ensayo de Lovecraft en la revista The Recluse en 1927, Carrere ya se había pronunciado sobre el asunto. Así, en «La rebelión de los fantoches» (La Novela Semanal, 1925), el autor manifestaba 
que «lo inquietador radica en la escasa seguridad que tenemos de su existencia» $(2010,59)$. Tal afirmación no debe entenderse como una declaración por un gusto estético hacia lo inverosímil, sino más bien en términos de lo que Sigmund Freud denominaba «siniestro» [Unheimlich]: «lo siniestro sería aquella suerte de espantoso que afecta a las cosas conocidas y familiares desde tiempo atrás. [...] lo siniestro causa espanto precisamente porque no es conocido, familiar» (Freud 1973, 2484). Así, este sentimiento, ejemplificado por Freud a través de la literatura de E. T. A. Hoffmann, surgiría a la vista de un elemento inexplicable que choca con el entorno conocido. Por tanto, una de las vías del horror se encuentra en la extrañeza que provoca lo imposible en el lector, que se siente imposibilitado de racionalizar lo desconocido, la «alteridad» (Jackson 2001, 143-144). De esta forma, el objetivo de lo fantástico debía perseguir el extrañamiento del lector por medio de la inclusión de elementos cuyo funcionamiento fuera ajeno a su cotidianeidad ${ }^{7}$.

Siguiendo semejante premisa, Carrere persigue el efecto de horror en su narrativa a través de algunos procedimientos concretos. Por un lado, el autor manifiesta su gusto por motivos tradicionales, tales como fantasmas, revinientes, casas encantadas, brujas y diablos, en los que de forma tan prolija se había fijado la novela gótica (Hogle 2011, 2) y que traspasaría la literatura fantástica, que elaboraría catálogos interminables (Todorov 1999, 82-83). Sin embargo, el autor madrileño reviste estos motivos de una pátina de modernidad. Esta suerte de renovación se construye concretamente a través del prisma ocultista $(\mathrm{Ca}-$ sas 2009, 367-371) muy en boga en la época finisecular hispánica, que no se podía sustraer de la «moda por el misterio» iniciada en Europa sobre todo a partir de célebres casos como el de Victor Hugo ${ }^{8}$. Así, en la época finisecular y modernista abundarán los sociedades y publicaciones espiritistas y teosóficas en España e Hispanoamérica (Correa Ramón 2006, 272 y 274-275 y 2019), que difundían las ideas de los respectivos impulsores, Allan Kardec y Madame Blavatsky, así como de otros iniciados (Celma Valero 1989, 137-142; Gullón 1990, 133-152; Palacios 2009, 13-44). Este ambiente de misterio inundará la obra de autores como Emilia Pardo Bazán, Rubén Darío, Ramón del Valle-

${ }^{7}$ En esta línea, Prieto de Paula afirma, entendiendo el miedo como efecto primordial de lo fantástico, que «irrumpe más efectivamente cuando los mecanismos de defensa contra el mismo no están programados para intervenir, lo que requiere que se cree [el miedo] en un contexto normal en el que las expectativas quedan burladas» $(2002,254)$.

${ }^{8}$ A pesar de los tempranos experimentos espiritistas de Victor Hugo (desde 1853 a 1855), la implantación oficial de la primera sociedad espiritista española se produce prácticamente en las mismas fechas; concretamente, será en 1855 cuando se funde la Sociedad Espiritista de Cádiz. Dos años más tarde se produjo la primera publicación sobre el tema en la Península, y en 1888 se celebró en Barcelona el primer Congreso Internacional espiritista (Gullón 1990, 135-140). 
Inclán, Amado Nervo o Leopoldo Lugones y de otras figuras hoy menos conocidas como Amalia Domingo Soler, Mario Roso de Luna o Ángeles Vicente.

Viviendo en esta atmósfera, Carrere no podía mantenerse al margen del ocultismo (Labrador Ben 2006). Aparte de su amistad con Roso de Luna, teósofo y gran divulgador de las ideas de Blavatsky, la penetración de este fenómeno en el ambiente literario alcanzará tal magnitud que la moda se tornará tendencia estética, nuevo prisma a través del cual contemplar y analizar la realidad $^{9}$. Influenciado por sus contactos con las ciencias ocultas, el autor madrileño interpretará algunas de sus lecturas fundamentales, como la obra de Edgar Allan $\mathrm{Poe}^{10}$, una de las mayores influencias para las letras hispánicas en el cambio de siglo (Casas 2009, 360-364). En este sentido, Carrere se expresaba sin tapujos en su artículo «Edgar Poe, ocultista»" :el caso de "Ligeia" no se inventa, ni el de "Morella" tampoco, sin poseer, además de la imaginación, una completa identificación con lo extraterrestre, juntamente con una honda y difícil cultura ocultista» (Carrere 2010, 127). El ocultismo encarna por tanto una de las caras de la literatura fantástica finisecular, una clave estética particular del modernismo y de la modernidad literaria, que elabora, a través de la creencia en los espíritus, una propuesta de salida al riguroso cientificismo de inicios del XX.

9 Sobre la gran popularización del espiritismo alertaba un preocupado Marcelino Menéndez Pelayo en la Historia de los heterodoxos españoles (1881), afirmando que estas sociedades «cuentan con más afiliados que todas las variedades de protestantismo juntas, y que todos los sistemas de filosofía racionalista» (cit. por Gullón 1990, 140). Uno de los trabajos que más atentamente analiza el espiritismo en la literatura española del modernismo, al tiempo que describe sus prácticas y creencias es el de Lily Litvak (1994). En cuanto a la teosofía, no existen mejores testimonios que los de Mario Roso de Luna y Leopoldo Lugones, uno de los más activos teósofos del modernismo hispanoamericano (Lugones 1902).

${ }^{10}$ El contacto de Carrere con Edgar Allan Poe fue constante, lo que se observa en las continuas menciones del autor norteamericano y de sus personajes; entre ellos, su obsesión por Ligeia será mayúscula, dedicándole varios cuentos y poemas, como el homónimo incluido en algunas de las ediciones de Dietario Sentimental (1919) o el cuento «El espectro de la rosa» (Almas, brujas y espectros grotescos, 1919). Queda todavía analizar con rigor la gran influencia de Poe en La torre de los Siete Jorobados (1924). Aquí son rastreables los ecos tanto del Poe policiaco («The Murders in the Rue Morgue», Graham's Lady's and Gentleman's Magazine, 1841) como de su faceta más misteriosa y terrorífica presente en «The Black Cat» (United States Saturday Post, 1843), «The Imp of the Perverse» (Graham's Lady's and Gentleman's Magazine, 1845) o "The Facts in the Case of M. Valdemar» (American Review, 1845), en donde el mesmerismo y la hipnosis representarán los principales motores de la narración. La experiencia de Carrere ante la literatura de Poe llegará también en su labor como traductor (Historias extraordinarias, prólogo de Carlos Baudelaire, trad. de Emilio Carrere, col. Autores Célebres Extranjeros, Madrid, Matev, s.a).

${ }_{11}$ Existe una edición reciente de otros artículos espiritistas de Carrere, agrupados en «Artículos y textos espiritistas» (Carrere 2009, 221-242). 
Todos estos elementos vertebran un volumen misceláneo que Carrere tituló Almas, brujas y espectros grotescos (Interrogaciones al Misterio) (1919). En esta obra, a artículos como el ya citado sobre Poe, acompañarán diversas narraciones, como «Embrujamiento», donde la influencia de las artes ocultas será nuclear. Aquí, el protagonista del relato será forzado a participar en una sesión espiritista en la que, una vez ha entrado en trance, asesinará al burlador de su prima. En este caso, el efecto de horror catártico se consigue de forma indudable, por lo que el recubrimiento pseudocientífico ${ }^{12}$ de lo sobrenatural que se podría argüir en contra de la filiación fantástica del relato no funciona más que como un procedimiento más al servicio de lo imposible. Así, el ocultismo y su pátina de cientificismo sirve al autor para «intensificar la verosimilitud, para hacer creíble la historia a un lector que cada vez conoce mejor el género y, por tanto, al que cada vez resulta más difícil impresionar» ${ }^{13}$ (Casas 2009, 360). Ello no implica que lo fantástico sea aceptado sin fisuras en la obra de Carrere, presentándose frecuentemente numerosas vacilaciones entre lo real y lo insólito.

\subsubsection{Entre el horror y el distanciamiento}

El extenso corpus carreriano muestra numerosos casos de atenuación del efecto fantástico, sobre todo en relación con el humor, uno de los rasgos más notables de su poética, en constante duda formal y genérica, como se aprecia en la recurrencia a la parodia. Este y otros procedimientos desmitificadores pueden alcanzar a cuestionar lo sobrenatural, tal y como se evidencia en relatos como «El destino payaso» (La Novela Corta, 1922), «Los muertos huelen mal» (Los fantasmas y otros cuentos, s.a) o en «El diablo de los ojos verdes» (La Novela de Hoy, 1922). En esta última narración, encontramos muestras del magistral efecto de horror carreriano, asimilable a la turbación que describía Ann Radcliffe por oposición al efecto de terror: «Terror and horror are so far opposite, that the first expands the soul, and awakens the faculties to a high degree of life; the other contracts, freezes, and nearly annihilates them» $(1826,149)$. Así, mientras que el terror suponía un sobresalto que «expandía el alma» y sus facultades, por el contrario, el horror las «congelaba», anulando la razón del sujeto. Por su par-

12 Siguiendo el prisma pseudocientífico del espiritismo, los personajes de Carrere explican la existencia de los fantasmas: «... eso se llama la exteriorización de la motilidad, un desgajamiento inconsciente de nuestra energía» (Carrere 2010, 66).

13 Ya Heinrich Heine advertía irónicamente sobre la renovación que debía llevar a cabo la literatura fantástica, haciendo notar cómo a finales del romanticismo los fantasmas tradicionales empezaban a tener poca verosimilitud para el lector: «¿Cómo puede ser un francés un fantasma? ¿Cómo van a existir fantasmas en París? ¡En París, en el hogar de la sociedad europea! Entre las doce y la una, la hora en la que, desde siempre, los fantasmas pueden y deben trabajar, sigue hirviendo la vida más activa en las callejuelas de París; [...] todo corre y bailotea, y ríe y gasta bromas por los boulevards, y va de soirée» (Heine 2015, 266). 
te, Stephen King elaboraba una tríada de conceptos bastante semejantes a los de su predecesora. En esta ocasión, el autor oponía la repulsión y el terror al horror, entendido como «emoción que subyace bajo el terror; una emoción ligeramente menos refinada porque no pertenece únicamente a la mente. El horror también provoca una reacción física mostrándonos algo que es físicamente perturbador» $(2016,50)$. Carrere se deleitará produciendo en el lector estas variedades de miedo «físico»y «metafísico» (Roas 2011, 95- 99):

La angustia le asfixiaba con la estrangulación glacial de sus garras invisibles. Ofidios escamosos, metálicos, brillantes se le enroscaban en las piernas y se le ceñían al vientre. Estaba envuelto en un ambiente sulfúrico, como debe ser la atmósfera del infierno, y le rodeaba una fauna inverosímil. Abejorros negros, corpúsculos enormes, como vistos a través de un microscopio gigantesco; moscas azules, como las lucilias de la descomposición cadavérica; mariposas peludas de rostros semihumanos; millones de larvas minúsculas flotando en el aire, de aspecto multiforme, como agigantados microbios de todas las epidemias. Y de todos emanaba un hedor caliente e insufrible que le secaba la garganta y le penetraba por los oídos. [...] La mueca de lo Horrible, el latigazo del Espanto, el sortilegio de la Alucinación (Carrere 2010, 47).

En este caso, el efecto de horror se consigue de forma plena por el sentimiento de amenaza experimentado ante el asalto psicológico de seres monstruosos y repulsivos. En última instancia, Carrere concentra en su prosa los tres niveles que King delimitaba en su definición del género (2016, 50-51): al horror que experimenta el protagonista se une el terror (miedo psíquico) al emanar el episodio de un estado puramente mental; al mismo tiempo, se siente la repulsión y el asco ante presencia (plenamente sensorial) de los insectos ávidos del festín putrefacto ${ }^{14}$.

Pese al efecto de horror conseguido, la dificultad genérica que plantea «El diablo de los ojos verdes» resulta evidente. De forma general, el problema es esbozado por el narrador, cuya ironía constante al retratar a sus personajes da

${ }^{14}$ Sin voluntad de entrar en prolijas disquisiciones terminológicas, como se puede apreciar, empleamos a lo largo de este trabajo el concepto «horror» asumiendo un valor muy concreto. Por un lado, se va más allá del «horror» en términos tan abarcadores como los que asume Ann Radcliffe para referirse a alteraciones psicológicas de gran violencia, o ante cualquier presencia de lo macabro $(1826,147-178)$. Sin embargo, por otra parte, se atiende a la suspensión del orden natural que veía la autora británica en el efecto de horror, acompañándose de un componente paralizante (González Grueso 2017, 37) que lo distingue del «terror», como en la misma línea afirma posteriormente Stephen King, contraponiendo el terror como estado predominantemente psíquico. Por otra parte, para el análisis de los relatos escogidos de Carrere, se desecha el concepto de «miedo» por entenderlo poco delimitador y ajeno en ocasiones a los matices que introducimos en este estudio. No obstante, empleándose una perspectiva general, es evidente que todos los fenómenos fantásticos aquí descritos podrían entenderse como diferentes formas de miedo (Ordiz Alonso-Collada 2014, 35-36; González Grueso 2017, 37-46). 
cuenta de la escasa fiabilidad de estos (Sánchez Torre 2002, 286-287). Así, queda constituido, junto a las alteraciones narrativas y los símbolos y sugerencias que plagan los textos modernistas, uno de los mecanismos de ambigüedad de lo fantástico finisecular (Casas 2017, 32-38). La consecuencia de ello resulta radical, hasta el punto de deslegitimar el elemento insólito que inicialmente nutría el relato. Una vez que se explica el elemento «sobrenatural», se anula de forma completa el discurso fantástico: «Era el ansia de placer contenida durante muchas noches de tempestad sensual, en las celdas del seminario, lo que estallaba, como una locura demoníaca y lúbrica, bajo el cráneo del clérigo fanatizado» (Carrere 2010, 26-27). Así, las horribles visiones nocturnas del sacerdote protagonista, y en última instancia, su presunta posesión demoníaca queda racionalizada. Al final, el narrador revela cómo la motivación de la salvaje trama se hallaba en la lujuria del protagonista, un obseso sexual que seduce y viola a las religiosas del convento. Estos relatos representarían ejemplos claros de la categoría de lo «pseudofantástico» o lo «fantástico explicado», que adquiere una forma muy desarrollada en los cuentos grotescos y paródicos de lo sobrenatural (Roas 2011, 62 y 73-74). En estos casos, la utilización de la ironía por parte de Carrere sería una de las consecuencias de ciertos «peligros» del humor en contacto con lo fantástico, como ya advertía el mismo Lovecra$\mathrm{ft}$ : «No me gusta el humor como ingrediente del relato sobrenatural; a decir verdad, creo que es un elemento indudablemente atenuante» $(2010,326)$. En el caso de Carrere resulta claro que, en esta parte de su producción, el ambiente paródico-grotesco sirve más al humor amargo y distanciado ${ }^{15}$ (Bravo 1997, 130) que denuncia una realidad social de ignorancia y superstición que al efecto de horror fantástico.

Junto a estos relatos de distanciamiento de lo extraordinario, encontramos otros textos en los que lo imposible no se anula en ningún momento. Además, como si se siguiera al milímetro las prospecciones de Lovecraft, se persigue el efecto de horror prestigiando la creación de una atmósfera inquietante: «El ambiente es primordial, ya que el criterio terminante de autenticidad no es el ensamblaje de una trama, sino la creación de una sensación determinada» (Lovecraft 2010, 31). En este sentido, Carrere se suele servir de elementos de la tradición gótica para crear efectos sobrenaturales, para los que Ann Radcliffe aconsejaba acudir a la imaginación para conseguir una atmósfera oscura, que

${ }^{15}$ Leopoldo Sánchez Torre, en su estudio sobre La torre de los siete jorobados llega a concluir en la total «anulación del efecto atemorizante» a través del particular humor carreriano, que llega a aproximarse al esperpento: «Su humor es disparatado, $\mathrm{y}$, si generalmente es castizo, fácil y hasta chabacano, otras veces apunta algún rasgo vanguardista, en la estela del absurdo e incluso del esperpento. Es un humor que, en última instancia, anula el efecto atemorizante característico del relato de miedo. Podríamos decir, en consecuencia, que, en la novela [...], el miedo no existe en realidad, y ello porque los autores han desplegado recursos que a la vez que lo convocan lo revocan» $(2002,302)$. 
difiriera de lo cotidiano: «The wild attire, the look not of this earth, are essential traits of supernatural agents, working evil in the darkness of mystery». Continuando este argumento de «desfamiliarización», la autora concluía afirmando que cuando el ambiente se torna familiar, «la ilusión se desvanece» (Radcliffe 1826, 147). Como siguiendo al pie de la letra estos preceptos, «La casa de la cruz» (La novela de hoy, 1924) gira en torno al eje espacial, cuyo trasunto sobrenatural se recrea de forma fantasmagórica.

La narrativa carreriana alberga numerosas sorpresas, entre las que se encuentra la relectura de modelos literarios, tal y como se anticipaba en el caso de Poe. En esta ocasión, pese a la ambientación espectral de su relato, introduce un toque novedoso: lejos de recurrir a la tópica ambientación de castillos, ruinas y páramos misteriosos de las novelas dieciochescas, o del ambiente rural y folklórico de los relatos de Valle-Inclán, Carrere sitúa su acción en la ciudad. Concretamente, será el Madrid legendario de los Austrias el escenario donde se desarrollará la trama, aunque evidentemente, la metrópoli ha sufrido una radical transformación literaria:

Las añosas plazoletas, y los angostos pasadizos, se pueblan por la noche de fantasmas de capa y espada. [...] Yo tengo una devota afición por ese barrio del viejo Madrid, [...] cuando se han encantado los relojes y aún vivo en el corazón de los siglos pretéritos. Parece una ciudad pequeñita, que por arte de magia sobrevive al margen de la tumultuosa ciudad moderna (Carrere 1924, 11-12).

Se construye así el espacio fantástico, nocturno, atemporal y fantasmagórico, la cara oculta de la urbe moderna. En esta zona «otra» de lo urbano, que se regirá mediante diferentes reglas de funcionamiento, se podrá localizar el motor de lo imposible. Para ello, Carrere recurre al motivo tradicional de la casa encantada: «En seguida abrió con suavidad la puerta y me invitó a seguirle. Un soplo húmedo me dio en la cara, como el hálito de un subterráneo. La puerta no había crujido. Yo no vi ninguna llave en la mano del sacerdote» (1924, 17). Así se describe la entrada del narrador a la Casa de la Cruz, el acceso al misterio mediante una sutil pincelada sobrenatural (una puerta que se abre sola) y que luego se enriquecerá con multitud de elementos de tradición gótica: «La obscura escalera era pina y vieja, de peldaños crujientes [...]. Las arañas colgaban sus telares de los rincones [...] a solas, en una casa deshabitada, en medio de la noche, con un fantasma auténtico» $(1924,19)$. Mediante esta ambientación de casa encantada, otro de los espacios de lo siniestro para Freud (1973, 2498), la entrada de los protagonistas a la Casa de la Cruz representará un descenso a los infiernos en toda regla.

Junto a los elementos anteriores, Carrere recurre para la delimitación del espacio fantástico al aludido ocultismo, otro lugar común del imaginario finisecular y que, en muchas ocasiones, se construía como herencia directa del decandentismo francés. Este es el caso de uno de los componentes de las ciencias ocultas, el satanismo, tan en boga a partir de la novela de Joris-Karl 
Huysmans Là-bas [Allá Lejos] (1891). Quizás se encuentre aquí uno de los posibles hipotextos para la consecución de la atmósfera terrorífica del relato, cuyo clímax se alcanza en el episodio de la celebración de una misa negra. Esta herética ceremonia correrá a cargo del brujo Exili, al que se le había encomendado la curación del hechizo del rey: «En el altar había un crucifijo invertido, y al encenderse las luminarias vi, con espanto inaudito, que sobre la figura del Salvador había un monstruo. Era el Baphomet de los templarios, el macho cabrío, con una luz entre los cuernos, con cuerpo de varón y pechos de mujer» (1924, 50). Ante la culminación del ritual satánico, la reacción del sacerdote que lo presencia (y que posteriormente narra lo vivido al narrador del relato marco) no puede ser menos que de absoluto horror:

De repente oí un grito, que me entró como una espada en el corazón. Volví el rostro y ví un espantoso espectáculo. Aquel hombre siniestro que había al pie del ara, a un mandado de Exili, de un solo tajo, había decapitado al blanco comulgante. El verdugo del rey empapaba la sangre inocente, que fluía por las escalinatas del altar [...]. Exili recogió la cabeza de la víctima y la colocó sobre la forma negra, sobre un gran copón de oro y esmeraldas, en la mesa, vestida de negros terciopelos. Los ojos abiertos del niño, en un espanto infinito, se clavaban en la noble dama. Aquellos ojos, que se iban vidriando lentamente, aterrorizaban al pálido enfermo, cuyo mal no sabían los físicos, ni los teólogos, ni los nigrománticos $(1924,51)$.

De forma muy hábil, Carrere no se limita a describir este terrible episodio, sino que gracias a su técnica perspectivista comparte la reacción horrorizada de los espectadores. Entre ellos se incluye al lector, que se identifica con la angustia que sienten los personajes ante los escabrosos hechos presenciados: la profanación de la eucaristía en la más extremada misa negra, que culmina en la sangrienta decapitación de un niño.

El final del relato no puede ser más pavoroso: la fija mirada de la cabeza decapitada sobre los asistentes (y el lector), se va tornando vidriosa con la llegada de la muerte. Como se ha advertido, Carrere hace hincapié en la horrorizada reacción de los asistentes al ritual. En relación con estos personajes, simultáneamente espectadores y participantes del rito, entra en funcionamiento una compleja subcategoría del horror que era definitivamente identificada por Julia Kristeva mediante su concepto de «lo abyecto»:

Hay en la abyección una de esas violentas y oscuras rebeliones del ser contra aquello que lo amenaza y que le parece venir de un afuera o de un adentro exorbitante, arrojado al lado de lo posible y de lo tolerable, de lo pensable. Allí está, muy cerca, pero inadmisible. Eso solicita, inquieta, fascina el deseo que sin embargo no se deja seducir. Asustado, se aparta. Repugnado, rechaza, un absoluto lo protege del oprobio, está orgulloso de ello y lo mantiene. Y no obstante, al mismo tiempo, este arrebato, este espasmo, este salto es atraído hacia la otra parte tan tentadora como condenada. Incansablemente, como un bumerán indomable, en 
polo de atracción y de repulsión coloca a aquel que está habitado por él literalmente fuera de sí $(1989,7)$.

En estos términos, los asistentes a la misa negra experimentan una suerte de «horror abyecto» en tanto que se debaten entre el absoluto rechazo y la aceptación de los hechos presenciados; de alguna forma, todos comulgan de la doctrina satánica y están advertidos de lo que van a presenciar. En todos los casos, esta modalidad de horror repele y atrae al mismo tiempo a los personajes, que se introducen de lleno en el huracán de violentas perversidades que el modernismo más oscuro no cesaba de poetizar. Puede entenderse así esta modalidad satánica de lo fantástico en su utilización del horror como vehículo de expresión primordial de lo oculto, de los terrores ante la «otredad» (Carrera Garrido 2015, 78) y de los deseos del subconsciente (Casas 2009, 365; Aldana Reyes 2016, 11), generados al margen de las convenciones sociales (Punter 1980, 405 y 417). De esta forma, la consecución del horror satánico se inscribe en la «categorización estética del crimen» (Litvak 1979, 86) usual en las tendencias literarias finiseculares con las que Carrere no dejaría de comulgar.

Conforme avanza el relato hacia su final, no decrece el sentimiento de horror petrificante, lo que da cuenta de la pericia narrativa de Carrere en parte de su obra. Todo concluirá con la espectacular desaparición del mago, en una efectista culminación de lo fantástico:

Maese Exili, más astuto, o acaso asistido por sus poderes tenebrosos, huyó con la agilidad de un gato montés. Los hombres le persiguieron en vano. Desde la calle algunos le vieron sobre las tejas y oyeron su risa lúgubre y tableteante. Cuando le dispararon sus pistolas se desvaneció como el humo negro, dando saltos inverosímiles, de tejado a tejado. Algunos aseguraban que volaba caballero en un macho cabrío (Carrere 1924, 54).

En tanto que aliado del diablo, el brujo huye exhibiendo su poder sobrenatural, inmune por completo a las fuerzas humanas. De esta forma, el efecto de horror en el relato surge no solo a partir de lo repulsivo del crimen y de la profanación representada por la misa negra, sino en el desafío de las leyes de la Naturaleza, tal y como advertía Lovecraft: «el miedo es nuestra emoción más fuerte y profunda, y la que mejor se presta a la creación de ilusiones que desafíen a la Naturaleza. El horror, lo desconocido y lo extraño están siempre estrechamente relacionados» (Lovecraft 2010, 279). Así, entre las vías de llegada al horror no se encuentra únicamente la amenaza física o la visión de escenas violentas, sino la constatación «metafísica» de que lo desconocido ha entrado en contacto con nuestra realidad.

A pesar del despliegue de medios que ha dado lugar la narración de los acontecimientos acaecidos en la Casa de la Cruz, la conclusión del relato marco se mueve en una profunda ambigüedad. Este hecho se intensifica por las confesiones del narrador, que, horrorizado, ha terminado de escuchar la historia 
sobre la casa maldita: «Cuando me recobré de este relato de pesadilla, el clérigo había desaparecido, y me hallaba en la calle, absorto ante la medrosa Casa de la Cruz. Había salido el sol, que ahuyenta a los fantasmas» (Carrere 1924, 56). Este equívoco cierre puede mover a especular sobre una posible atenuación final del efecto fantástico. No obstante, ello debe entenderse como un recurso más del género. A través de esta pincelada de ambigüedad, se insta al lector activo $^{16}$ (Herrero Cecilia 2000, 193-195) a que tome partido ante lo amenazador (Roas 2001, 20; 2011, 32-33) de la literatura fantástica. En última instancia, el narrador, que ha llevado de la mano al lector junto a los personajes, desaparece bruscamente para pasar el testigo al receptor del relato, que debe decidir si Maese Exili huyó por su astucia o ayudado por sus poderes mágicos; si el relato fue un sueño o si realmente existió el clérigo narrador. No existe aquí por tanto la paródica desarticulación de lo insólito mencionada en los anteriores relatos, sino una herramienta más de lo fantástico para conseguir el extrañamiento último del lector.

Carrere utilizará el tema del sueño todavía de forma más directa en «La rebelión de los fantoches» (La Novela Semanal, 1925). En este caso, el elemento fantástico principal será la aparición de una serie de personajes de ficción a su creador (alter ego del propio Carrere). A través de su presencia, los personajes acusan al escritor del maltrato recibido y de haberlos construido defectuosos e inscritos en un medio miserable en el que han sido abandonados a su suerte. Ante lo inverosímil de este hecho, Carrere esgrime su humor ácido y castizo. Sin embargo, en este caso, la burla no atenuará lo sobrenatural, sino que servirá como una herramienta más para otorgar mayor verosimilitud a lo fantástico:

-¿Me estaré volviendo loco? -se preguntó con pánico; pero se tranquilizó, recordando que aquella tarde le había pedido un amigo - de esos pegadizos, cuyo nombre ignoramos- que le prestase doscientas pesetas, y él se había excusado. Con esa sólida garantía de su buen funcionamiento mental, sonrió y pidió el menú (Carrere 2010, 60).

Una vez construido este fuerte anclaje de credibilidad, y alcanzada la confianza del lector, el narrador pasa a describir la galería de disparatados encontronazos entre el autor protagonista y sus criaturas de ficción. Una vez más, se busca el efecto de horror sobre sus personajes y el lector a través de escenas grotescas.

-¡Ah, ya sé quién eres tú! [...] ¡la mujer sin cara!

-Sí, yo soy; pero no huyas de mí, porque te deseo [...] ¡Ten piedad de este pobre monstruo de lujuria, que es obra tuya...! [...] ¡Quiero besarte en la boca! -y

${ }^{16}$ El mismo Lovecraft aludía al lector activo en su clásico ensayo, cuando afirmaba que lo fantástico «exige del lector una cierta dosis de imaginación y una capacidad de evasión de la vida cotidiana» $(2010,27)$. 
alargando el labio inferior, roído por un epitelioma, aplastó la boca del novelista en un beso que hedía y supuraba. Martín quiso gritar y la voz se le heló en la garganta; intentó huir, pero sus piernas no tenían sangre ni energía, parapléjicas, de repente, como en la angustia de una pesadilla. El loco erotómano y la mujer sin cara se reían de su pavor.

-¿No te gustan las sensaciones terribles, el escalofrío del espanto? $(2010,92)$.

Como en casos anteriores, el efecto de miedo aquí es eminentemente físico, su amenaza atenta contra la integridad física del personaje (Roas 2011, 95), por lo que consigue, tal y como afirmaba Ann Radcliffe, el efecto de «congelación» o parálisis que constituye el efecto de horror. Por otro lado, una vez más se alcanza la verosimilitud plena. Pese a lo imposible de la aparición (un personaje de ficción creado por el escritor protagonista), la naturaleza de la figura no se reviste de rasgos irreales o idealizados, sino del más absoluto realismo, marca de estilo de la tendencia no-exotista del modernismo (Martínez Cachero 1990, 97), al tiempo que útil para la creíble caracterización de lo fantástico (Roas 2011, 111-113). Con todo, la prosopografía de Carrere no está exenta de la exageración un tanto expresionista, intensificando los rasgos mediante el gusto naturalista-decadentista por lo enfermo.

En cuanto al procedimiento para conseguir el efecto de horror, Carrere recurre en esta ocasión al motivo del monstruo, que cumple con creces la prototípica caracterización del género:

Es crucial [...] que el monstruo sea considerado como amenazador e impuro. Si el monstruo fuera sólo evaluado como potencialmente amenazador la emoción sería miedo; si sólo fuera potencialmente impuro, la emoción sería repugnancia. El terror-arte requiere evaluación tanto en términos de amenaza como de repugnancia (Carroll 2005, 70-71).

Como se ha podido apreciar, el monstruo carreriano asume esta dicotomía constitutiva formada por el carácter amenazador y su impureza. Sobre el primer extremo, la mujer sin cara resulta amenazadora en tanto que su apariencia extraña y deforme (ausencia de rostro), introduce el caos en la normalización de la figura humana. En este caso, además, el monstruo se muestra enfermo, lo que supone una amenaza adicional al protagonista por medio del posible contagio ${ }^{17}$.

En cuanto al carácter impuro de la figura, todavía resultan de mayor calado las implicaciones. Por un lado, esta corrupción posee un sentido meramente físico de acuerdo con el cual el protagonista experimenta repulsión ante la putrefac-

17 En su caracterización mórbida de lo femenino, Carrere bebe de la tradición teratológica decadentista, que desde Les diaboliques (1874) de Jules Barbey D'Aurevilly, pasando por $\dot{A}$ Rebours (1884) de Joris-Karl Huysmans y la descripción femenino-alegórica de la Gran Sífilis (Huysmans 2012, 223-224), hacía de esta enfermedad uno de los atributos predilectos de la atrayente feminidad malsana, así como uno de sus principales peligros (Bornay 2016, 63-66). 
ción. No obstante, todo ello resulta susceptible de una lectura más profunda, acorde al misógino imaginario finisecular, repleto de figuras de perversidad femenina. En tanto que elemento siniestro, la mujer se encargará de introducir frecuentemente lo sobrenatural en el relato (Ben Slama 2016, 251-252). Sin embargo, estos personajes aparecen descritos usualmente con fascinación, como se aprecia en Los ojos de la diablesa (1913), narración publicada posteriormente como «El misterio de la casa de los gatos» (La Novela Corta, 1920) y El espadín del caballero guardia (1922). Sin embargo, conviene quedarse por ahora con el primer título, que manifiesta abiertamente la naturaleza demoníaca de la protagonista, así como su principal atractivo, los ojos:

Los ojos eran el hechizo más poderoso de aquella beldad, pues parecían poseedores de un sortilegio demoniaco y a los cambiantes de luz variaban de color y ya eran negros como dos cisternas de tentación, claros, con el cándido azul de los rompimientos de gloria; grises, como herméticos mares de acero, y verdes como los de las sirenas, como los de los gatos y como esos ojos ilusorios que muestra la luna, cuya mirada cruel hace delirar a sus pálidos ahijados (Carrere 1999, 315).

Durante toda la narración, la misteriosa doncella realizará esporádicas apariciones al donjuanesco Alfonso de Echenique, cada vez más enloquecido de deseo por la amada, que se esfumará de forma inexplicable varias veces ante sus ojos, haciendo gala de su poder sobrenatural. Al final, el idilio entre los personajes parece acercarse a la consumación cuando el amante divisa a la joven asomada a un balcón. Pero como en el caso de «La casa de la cruz», el espacio encantado desata lo insólito ${ }^{18}$ :

$\mathrm{Al}$ acercarse, vio con asombro que el balcón iluminado pertenecía a la casa misteriosa que siempre le había inquietado, a la mansión habitada antaño por las dos nobles y vetustas doncellas a quienes una noche devoraron unos gatos voraces y asesinos, mansión rodeada de una leyenda de maleficio y abandonada desde hacía muchos lustros $(1999,328)$.

Carrere construye así la entrada al recinto de la leyenda oscura (no exenta del particular humor negro carreriano), a un espacio por otro lado atemporal, donde no existe la muerte y el caballero puede gozar con un fantasma. A la salida de la misteriosa mansión, el protagonista retoma el contacto con lo cotidiano; el hechizo de la casa se ha disuelto al intentar penetrar de nuevo en ella, pero su espadín olvidado en uno de los salones advierte al lector sobre la realidad ficcional del elemento fantástico.

${ }^{18}$ La casa antigua y destartalada en apariencia, oculta usualmente en los relatos de Carrere un interior sorprendente: "Las casas tienen alma y también tienen rostro» (Carrere 1924, 12). En definitiva, estos espacios se construyen como entrada a lo fantástico, como ocurre en los casos mencionados de la "La casa de la cruz», Los ojos de la diablesa o en «La casa vieja» (Retablillo grotesco y sentimental, Madrid, s.a). 
El fantasma de los ojos verdes del relato transforma a Echenique. Profundamente trastornado, pone fin a sus escarceos y concluye sus días consagrado al retiro monástico, apoyándose en la religión al no poder explicar con la razón la naturaleza de lo vivido. De esta forma, y aunque se pueda deducir en este caso el efecto benefactor de la feminidad sobre la vida licenciosa del protagonista, lo femenino en la obra de Carrere asume generalmente un carácter maligno, en relación estrecha con la muerte (Ben Slama 2016, 256) y en deuda con el decadentismo. Estas imágenes, encabezadas por personajes antiguos (la Esfinge, Helena, Cleopatra) o bíblicos (Judith, Dalila, Salomé), se suelen revestir de atributos inhumanos y bestiales, disfrutando con la destrucción del hombre (Pedraza 1991, 108-109; Bornay 2016, 113-116 y 357-380), que por otra parte los desea (Lederer 1968, 252-253). Así ocurre en «El manto de oro de Salomé» (El cuento popular, 1914):

Se podría decir que sentía un miedo supersticioso a la mujer como un abismo infinito donde cantasen las sirenas de la muerte, como en la canción trágica de Loreley. [...] Carmela me absorbe toda la vida... Es un vampiro que devora mis energías, mi tiempo y mi inteligencia. [...] Goza dramatizando la vida; cuando besa, muerde; el placer es maceración, la caricia arañazo; me estruja, me aniquila, me convulsiona. Vivo en una llamarada permanente (Carrere 1914, 4 y 11).

Así, Carrere emplea el prototipo finisecular de la mujer fatal y maldita, que se articula en forma de terrible monstruo amenazador, como vampiro que se alimenta de la energía del hombre para aniquilarlo finalmente. Algo parecido se produce en «La conversión de Florestán» (La Novela Semanal, 1921), donde la caracterización de la deseada Angélica se completa de forma más siniestra. En este relato, el pacto diabólico que ha firmado el protagonista solo le permitirá poseer al fantasma de la amada, cuyo cuerpo termina pudriéndose de forma grotesca ante los brazos del donjuán ${ }^{19}$. En este sentido, la mujer sin cara de «La rebelión de los fantoches» podría representar una suerte de ajuste de cuentas de uno de los personajes femeninos del autor que, cansado del malditismo impuesto (voluptuosidad, perversidad y finalmente deformidad), se tornará mujer verdaderamente autónoma para vengase.

${ }^{19}$ Es posible identificar como fuente hipotextual de este relato El estudiante de Salamanca de José de Espronceda, donde se produce la mutación tenebrosa del espacio urbano, la caracterización del personaje femenino con la idealidad que también comparte la Angélica de Carrere y finalmente el motivo del beso a la amada muerta que se torna luego esqueleto. En general, la comparación entre el texto romántico y el modernista ofrece similitudes más que notables, no solo temáticas sino también estilísticas (Espronceda 2001, 272, vv.1554-1569; Carrere 1921, 59-62). En cualquier caso, a pesar de la concreta relación señalada, Carrere recrea el tópico del memento mori aplicado a lo femenino, que tradicionalmente hacía hincapié en la corrupción de la carne, tal y como se aprecia desde textos como El mágico prodigioso (1637) de Calderón de la Barca (Lederer 1968, 40). 
El final de este relato aporta más sorpresas; nuevamente, en relación con el tema onírico. Así, el narrador declara que todos los encuentros del protagonista con sus creaciones han sido fruto de un sueño. Sin embargo, este hecho no desvirtúa lo fantástico, tal y como puede advertirse de una lectura atenta. En primer lugar, el despertar no trae la desaparición de lo imposible, pues el señor Catafalco (una de las criaturas de las novelas del protagonista) ${ }^{20}$ sigue a su lado. Cabría hablar por tanto de un mayor desarrollo de lo fantástico al existir un trasvase de un personaje que pasa del sueño a la vigilia. En esta ocasión no existe ambigüedad alguna, pues Carrere, a través de la voz de su creación es muy claro sobre la naturaleza de los sueños: «No por haber sido un sueño ha dejado de ser realidad [...]. La rebelión de los fantoches es una cosa real con relación a la realidad del plano en que habitan». De esta forma, en línea con la narrativa de Unamuno (Niebla, 1914), Carrere produce un moderno juego metanarrativo en donde los personajes (como el Augusto Pérez unamuniano) reclaman sus derechos a su creador. Al mismo tiempo, se introducirá una intensa reflexión sobre el poder de lo fantástico en la realidad ficcional ${ }^{21}$.

Cabe preguntarse ahora por las motivaciones de la estética carreriana analizada en este trabajo, tradicionalmente interpretada como tendencia conservadora y escapista en un horizonte estético que se acercaba ya a la vanguardia. Sin embargo, un análisis detallado de los textos desmiente estas consideraciones. Los relatos analizados deben ser entendidos como producto de una matriz ideológica concreta que se expresa de forma contradictoria: el gesto radical de épater le bourgeois modernista (Sobejano 1967, 199-223) por medio de lo fantástico o de su actitud bohemia22 (Sánchez Álvarez-Insúa y Labrador Ben 2001, 407-408), se acompañaba de la dolorosa rendición a las exigencias del

${ }^{20}$ El señor Catafalco es el protagonista de numerosas obras de Carrere, como «El señor Catafalco» (Los Contemporáneos, núm. 496, 1916), relato reeditado posteriormente con diferentes títulos (Gutiérrez Barajas 2011, 306).

${ }^{21}$ La duda del personaje sobre su propia existencia y finalmente su intento de autoafirmación encuentra claro antecedente en la obra de Unamuno: «Empecé, Víctor, como una sombra, como una ficción; durante años he vagado como un fantasma, como un muñeco de niebla, sin creer en mi propia existencia, imaginándome ser un personaje fantástico que un oculto genio inventó para solazarse o desahogarse; pero ahora, $[\ldots]$ ahora me siento, ahora me palpo, ahora no dudo de mi existencia real» (Unamuno 2012, 251).

${ }_{22}$ Aunque la bohemia de Carrere pudo tener algo de impostura (Sánchez Álvarez-Insúa y Labrador Ben 2001, 407-408), no hay que olvidar la propia definición del autor sobre este fenómeno, entendiéndolo no tanto como forma material de vivir sino como modo de pensamiento, derivando así en una actitud vital manifiestamente subversiva: «La bohemia [...] es una forma espiritual de aristocracia, de protesta contra la ramplonería estatuida. Es un anhelo ideal de arte más alto, de una vida mejor; y por eso la situación de un bohemio es mucho más amarga, en la vida de relación, de lo que se creen los que se figuran que la bohemia está en el vestido o en las melenas descuidadas. [...] El bohemio es el individualismo rabioso» (Carrere 1999, 353). 
mercado (Rama 1985, 52-53). A pesar de ello, esta literatura termina representando otra salida al «vacío espiritual» de la época que ya diagnosticaban los románticos; «vivido como desgajamiento, este fenómeno se verá asignado en la vaga, amplia y renovada religiosidad que caracterizará el fin de siglo» (Phillips-López 2016, 33). Ante un horizonte social positivista y utilitarista, el desclasado intelectual acude al ocultismo para «dar un nuevo sentido a la vida» (Gutiérrez Girardot 1983, 143). Esto mismo es confesado por el propio Carrere en «El espectro de la rosa» (Almas, brujas y espectros grotescos): «Este drama, que se llama el Hombre, me parece que no termina bien con las escenas de carroña y de putrefacción. Y en un anhelo de dramaturgo idealista, sueño con una apoteosis, toda azul y oro milagroso, como un rompimiento de gloria para cuando caiga la cortina» (Carrere 2010, 125). Por tanto, la realidad ficcional de la narrativa fantástica de Carrere no es un escape de la realidad empírica; lo fantástico y el horror, sea cual sea su forma (gótica-tradicional, ocultista, irónica-grotesca o metanarrativa), se nutre de la realidad (desacralizada, industrial e injusta) con la que el artista moderno discrepa:

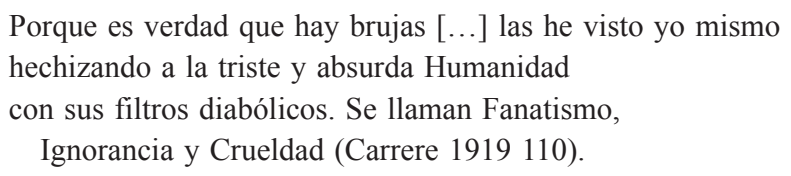

De esta forma, Carrere deja clara la naturaleza subversiva (Jackson 2001, 148-149; Roas 2001, 28) y comprometida de la literatura fantástica, una propuesta desde la literatura para una sociedad percibida como decadente.

\section{Conclusiones}

Frente a las críticas tradicionales sobre la falta de originalidad de la narrativa de Emilio Carrere, un análisis profundo y selectivo de su obra nos entrega valiosos frutos. En primer lugar, se muestra la frescura de un estilo multiforme, que supo conjugar objetivos frecuentemente comerciales con una original poética. A pesar de los tópicos finiseculares efectistamente presentados, así como de la ocasional facilidad de sus tramas, la prosa carreriana ensayó caminos de renovación estética a través de la literatura fantástica. Mediante la inserción de lo imposible en sus relatos, el autor madrileño buscó continuamente el efecto de horror mediante procedimientos tan diversos como la recurrencia a elementos sobrenaturales heredados de la tradición gótica (la casa encantada, fantasmas, monstruos) o los recursos metaficcionales. Con todo ello, el autor quiso reforzar el armazón de sus cuentos y novelas, otorgando verosimilitud al discurso fantástico (del que no pocas veces dudó) por medio de la justificación de lo imposible por vía ocultista y del distanciamiento a través del humor y lo 
grotesco. A través de todas estas operaciones narrativas y estilísticas, Carrere supo mantener por muchos años el pacto ficcional con sus lectores, que al tiempo que se traducía en éxito de ventas, ocultaba un ecléctico postulado estético en el que la realidad circundante era continuamente cuestionada.

\section{FuENTES}

Carrere, Emilio. 1914. «El manto de oro de Salomé». El cuento popular. 3. Madrid: Imprenta Artística de Sáez Hermanos.

Carrere, Emilio. 1919. Dietario sentimental. Madrid: Mundo Latino.

Carrere, Emilio. 1921. «La conversión de Florestán». La Novela Semanal, 6. Madrid: Prensa Gráfica.

Carrere, Emilio. 1924. «La casa de la cruz». La novela de hoy III, 99. Madrid: Sucesores de Rivadeneyra.

Carrere, Emilio. 1999. Antología. Ed. José Montero Padilla. Madrid: Castalia - Comunidad de Madrid.

Carrere, Emilio. 2009. Los muertos huelen mal y otros relatos espiritistas. Ed. Jesús Palacios. Madrid: Valdemar.

Carrere, Emilio. 2010. El diablo de ojos verdes y otros relatos. Madrid: Salto de página. Espronceda, José de. 2001. Obra poética. Ed. Jenaro Talens. Madrid: Biblioteca Nueva.

\section{BiBLIOGRAFÍA CITADA}

Addison, Joseph. 1991. Los placeres de la imaginación y otros ensayos de The Spectator. Madrid: Visor.

Aldana Reyes, Xavier. 2016. «Introduction: What, Why and When is Horror Fiction». En Horror: A Literary History, 7-17. Londres: British Library.

Ben Slama, Mohamed. 2016. «El género femenino como elemento amenazante: "La mujer alta", de Pedro Antonio de Alarcón y "La mujer sin cara", de Emilio Carrere». Brumal IV, 2: 247-260. http://doi.org/10.5565/rev/brumal.226

Borges, Jorge Luis. 1979. Otras inquisiciones. Madrid: Alianza Editorial.

Bornay, Erika. 2016. Las hijas de Lilith. Madrid: Cátedra.

Bravo, Víctor. 1997. Figuraciones del poder y la ironía. Esbozo para un mapa de la modernidad literaria. Caracas: Monte Ávila Ediciones.

Bravo Rozas, Cristina. 2013. La narrativa del miedo. Terror y horror en el cuento de Puerto Rico. Madrid: Verbum.

Burke, Edmund. 2014. De lo sublime y de lo bello. Madrid: Alianza Editorial.

Carrera Garrido, Miguel. 2015. «El terror sí tiene forma: delimitación teórica de una categoría estética». En Espejismos de la realidad. Percepciones de lo insólito en la literatura española (siglos XIX-XXI), coord. Natalia Álvarez Méndez y Ana Abello Verano, 75-84. León: Universidad de León.

Carroll, Noël. 2005. Filosofía del terror o paradojas del corazón. Madrid: A. Machado Libros.

Casas, Ana. 2009. «El cuento modernista español y lo fantástico». En Ensayos sobre ciencia ficción y literatura fantástica. I Congreso Internacional de literatura fantástica y ciencia 
ficción, Universidad Carlos III de Madrid, ed. Teresa López Pellisa y Fernando Ángel Moreno Serrano, 358-378. Madrid: Asociación Cultural Xatafi - Universidad Carlos III.

Casas, Ana. 2017. «El cuento modernista». En Historia de lo fantástico en la cultura española contemporánea, dir. David Roas, 15-38. Madrid: Iberoamericana Vervuert.

Celma Valero, María Pilar. 1989. La pluma ante el espejo (Visión autocrítica del Fin de Siglo, 1888-1907). Salamanca: Universidad de Salamanca.

Correa Ramón, Amelina. 2006. Hacia la re-escritura del canon finisecular. Nuevos estudios sobre las direcciones del modernismo. Granada: Universidad de Granada.

Correa Ramón, Amelina. 2019. «QQué mandáis hacer de mí?». Una historia desvelada de relecturas teresianas en el contexto cultural de entresiglos. Madrid: Iberoamericana Vervuert.

Cruz Casado, Antonio. 1994. «El cuento fantástico en España (1900-1936). Notas de lectura». Anthropos 154-155: 24-31.

Eagleton, Terry. 2005. Ideología. Una introducción. Barcelona: Paidós.

Freud, Sigmund. 1973. «Lo siniestro». En Obras completas, III, 2483-2505. Madrid: Biblioteca Nueva.

González Grueso, Fernando Darío. 2017. «El horror en la literatura». Actio Nova: Revista de Teoría de la Literatura y Literatura Comparada 1: 27-50. https://doi.org/10.15366/ actionova2017.1

Gullón, Ricardo. 1990. Direcciones del modernismo. Madrid: Alianza Editorial.

Gutiérrez Barajas, María José. 2011. «Catálogo de novelas de Emilio Carrere». Analecta Malacitana Electrónica 30. http://www.anmal.uma.es/numero30/Catalogo_Carrere.pdf

Gutiérrez Girardot, Rafael. 1983. Modernismo. Barcelona: Montesinos.

Heine, Heinrich. 2015. Sobre la historia de la religión y la filosofía en Alemania. La escuela romántica. Madrid: Tecnos.

Herrero Cecilia, Juan. 2000. Estética y pragmática del relato fantástico. Cuenca: Universidad de Castilla-La Mancha.

Hogle, Jerrold E. 2011. «Introduction: The Gothic in western culture». En The Cambridge Companion to Gothic Fiction, 1-20. Cambridge: Cambridge University Press.

Huysmans, Joris-Karl. 2012. A Contrapelo. Ed. y trad. Juan Herrero. Madrid: Cátedra.

Jackson, Rosie. 2001. «Lo "oculto" de la cultura». En Teorías de lo fantástico, comp. David Roas, 141-152. Madrid: Arco Libros.

King, Stephen. 2016. Danza Macabra. Madrid: Valdemar.

Kristeva, Julia. 1989. Poderes de la perversión. México: Siglo XXI.

Labrador Ben, Julia María. 2006. «Emilio Carrere y el ocultismo». En Bohemios, raros y olvidados, ed. Antonio Cruz Casado, 669-699. Córdoba: Diputación de Córdoba.

Lederer, Wolfgang. 1968. The Fear of Women. Nueva York: Harcourt Brace Jovanovich.

Litvak, Lily. 1979. Erotismo fin de siglo. Barcelona: Antoni Bosch.

Litvak, Lily. 1994. «Entre lo fantástico y la ciencia ficción. El cuento espiritista en el siglo XIX». Anthropos 154-155: 83-88.

Lovecraft, Howard Pilliphs. 2010. El horror sobrenatural en la literatura y otros ensayos teóricos y autobiográficos. Madrid: Valdemar.

Lugones, Leopoldo. 1902. «Nuestras ideas estéticas». Sophia. Revista Teosófica 5: 173-183.

Martínez Cachero, José María. 1990. «Modernismo no-exotista. ¿Cotidianismo, familiarismo, humildismo?». En El Modernismo. Renovación de los lenguajes poéticos, coord. Tomás Albaladejo, Javier Blasco y Ricardo de la Fuente, 93-104. Valladolid: Universidad de Valladolid.

Nora, Eugenio G. de. 1973. La novela española contemporánea (1898-1927). Madrid: Gredos. 
Ordiz Alonso-Collada, Inés. 2014. Manifestaciones ficcionales del terror. El gótico contemporáneo de las Américas. Tesis doctoral. Universidad de León.

Palacios, Jesús. 2009. «Emilio Carrere y los espíritus bohemios». En Los muertos huelen mal y otros relatos espiritistas, 9-48. Madrid: Valdemar.

Pedraza, Pilar. 1991. La Bella, enigma y pesadilla. Barcelona: Tusquets.

Pérez, Violeta. 1994. «Lo fantástico como categoría estética». Anthropos 154-155: 21-24.

Phillipps-López, Dolores. 2016. «Introducción». En Cuentos fantásticos modernistas de Hispanoamérica, 11-47. Madrid: Cátedra.

Prieto de Paula, Ángel Luis. 2002. «Escrituras del miedo». En Los dominios del miedo, ed. Vicente Domínguez, 251-266. Madrid: Biblioteca Nueva.

Punter, David. 1980. The Literature of Terror. A History of Gothic Fictions from 1765 to the Present Day. Londres: Longman.

Radcliffe, Ann. 1826. «On the Supernatural in Poetry». The New Monthly Magazine and Literary Journal, 145-152. Londres: Henry Colburn.

Rama, Ángel. 1985. Rubén Dario y el modernismo. Caracas: Alfadil.

Roas, David. 2001. «La amenaza de lo fantástico». En Teorías de lo fantástico, comp. David Roas, 7-44. Madrid: Arco Libros.

Roas, David. 2011. Tras los límites de lo real: Una definición de lo fantástico. Madrid: Páginas de Espuma.

Roas, David y Ana Casas. 2008. «Prólogo». En La realidad oculta. Cuentos fantásticos españoles del siglo XX, 9-56. Palencia: Menoscuarto.

Rodríguez, Juan Carlos. 1990. Teoría e historia de la producción ideológica. Las primeras literaturas burguesas. Madrid: Akal.

Sánchez Álvarez-Insúa, Alberto y Julia María Labrador Ben. 2001. «Emilio Carrére en la revista Por esos mundos (1906-1915)». Anales del Instituto de Estudios Madrileños 41: 393-417.

Sánchez Torre, Leopoldo. 2002. «Para reírse de miedo: humor y autoconsciencia en La torre de los siete jorobados». En Los dominios del miedo, ed. Vicente Domínguez, 281-302. Madrid: Biblioteca Nueva.

Sobejano, Gonzalo. 1967. «“Épater le bourgeois” en la España literaria del 1900». En Forma literaria y sensibilidad social, 178-223. Madrid: Gredos.

Todorov, Tzvetan. 1999. Introducción a la literatura fantástica. México: Coyoacán. Unamuno, Miguel. 2012. Niebla. Ed. Mario J. Valdés. Madrid: Cátedra.

Fecha de recepción: 30 de mayo de 2018.

Fecha de aceptación: 12 de noviembre de 2018. 